\title{
Which Target Population for Promotion Programs on Health Infant Feeding Practice in Laos?
}

\author{
Viengsamay Sengchaleun ${ }^{1,2 *}$, Daniel Reinharz ${ }^{1}$ \\ ${ }^{1}$ Department of Social and Preventive Medicine, Laval University, Quebec City, Canada \\ ${ }^{2}$ Faculty of Nursing, Laval University, Quebec City, Canada \\ Email: *viengsamay.sengchaleun.1@ulaval.ca
}

How to cite this paper: Sengchaleun, V. and Reinharz, D. (2021) Which Target Population for Promotion Programs on Health Infant Feeding Practice in Laos? Food and Nutrition Sciences, 12, 818-825. https://doi.org/10.4236/fns.2021.128061

Received: July 11, 2021

Accepted: August 20, 2021

Published: August 23, 2021

Copyright $\odot 2021$ by author(s) and Scientific Research Publishing Inc. This work is licensed under the Creative Commons Attribution International License (CC BY 4.0).

http://creativecommons.org/licenses/by/4.0/

\begin{abstract}
One of the determinants of the poor improvement in child nutrition indicators observed in Laos is mothers' feeding practices. These practices are influenced by many socio-environmental factors and are expected to be targets of public health programs against malnutrition. The purpose of this work is to examine how the Lao National Nutrition Strategy (NNS) incorporates the issue of the determinants of the behavior of mothers of young children in its recommendations. We argue that the little consideration brought in the NNS to key determinants of women's behavior is a major explanatory factor for the poor performance in improving the nutrition status of Lao under-five-year-old children.
\end{abstract}

\section{Keywords}

Determinant of Infant Feeding, Lao PDR, Mother, Nutrition Strategy

\section{Introduction}

Nutrition is a determinant of the ability to fully benefit from one's potential at birth. Optimum nutrition reduces morbidity and mortality, minimizes the risk of chronic diseases, and promotes overall healthy development [1]. After the age of two, it is much more difficult to reverse the undesirable effects of malnutrition [2]. To this effect, the World Health Organization (WHO) has issued recommendations for infant and young child feeding. During the first six months of life, an infant should be fed exclusively with breast milk, if the nutritional status 
of the mother makes her able to provide sufficiently nourishing milk. From the sixth month, breast milk must be supplemented with other foods that meet children's caloric and micronutrient needs [1].

Malnutrition is a public health problem in Laos, as in many developing countries. The importance of the problem can be seen through child mortality. In 2019, the under-five mortality rate was 46 per 1000 live births, a high rate compared to neighboring countries (9 per 1000 in Thailand, 20 per 1000 in Vietnam, and 27 per 1000 live births in Cambodia) [3]. In Laos, it is estimated that nearly $45 \%$ of these deaths are due to malnutrition [4]. The importance of malnutrition in Laos is also reflected in proper indicators of malnutrition. In 2017, stunting was estimated to affect $33 \%$ of Lao children under five. Underweight, on the other hand, affects $21 \%$ of children. These rates are higher than those in neighboring countries. On the other hand, the rate of wasting is lower (9\%) [5]. These indicators suggest that is, above all, a problem of chronic malnutrition.

In Laos, poor feeding practices were identified as one of the factors influencing child malnutrition [6]. Indeed, infant feeding practices are not always adequate in urban and rural areas [7] [8] [9] [10]. The prevalence of food restriction is about $90 \%$ in the population [7]. The Exclusive breastfeeding rate in the first six months is low (45\%) [5]. Too early introduction of non-milk food, such as glutinous rice, for example, is common. About $20 \%-50 \%$ of infants are given pre-chewed glutinous rice in the first week of life [11]. Colostrum is another example. In some ethnic groups like the Leu, Khamu, Phunoi, and Hmong, many mothers reject the colostrum, the milk produced in the first three days after birth, thinking that this milk, which is rich in micronutrients and antibodies, can cause diarrhea [9]. Infants are rather fed with honey or glucose until white breast milk appears. In addition, there are food taboos. For example, many people belonging to the Lue ethnic group believe that eggs delay dentition or cause dental problems. Many people of the Akha group believe that duck makes the child dumb, while many Lue people think that duck is one of the best foods for children. Food taboos for young children are common, especially during illness. Such taboos are likely to contribute to malnutrition and micronutrient deficiencies, especially where food variety is already limited [9]. Mothers' feeding behaviors are a key determinant of their child's nutritional status.

The purpose of this work is to examine how the Lao National Nutrition Strategy incorporates the issue of the determinants of the behavior of mothers of young children in its recommendations.

\section{Determinants of Inadequate Infants Feeding in Laos}

The underlying causes of non-optimal infant feeding, defined as nonexclusive breastfeeding until six months of age, and non-breastfeeding complemented by solid food from six months to two years of age, can be categorized into three major dimensions: inadequate access to services; inadequate financial and human resources and the socio-cultural and economic context [6]. 


\subsection{Inadequate Access to Services}

\subsubsection{Low Access to Health Services}

Living in remote areas is associated with malnutrition mainly because there is less access to health care services, in particular prenatal and postnatal care, where information about infant feeding is generally provided [9] [12]. Many women (36\%) who live in rural areas without roads do not benefit from antenatal care [5]. In addition, 35\% of women give birth at home without help from a well-trained health professional who can provide information on how to feed their child [5].

\subsubsection{Ability to Transfer Nutrition Information to Women}

Women who attend antenatal clinics may not be optimally informed about how to feed their future children because of the low capacity of health professionals to transfer nutrition information to women. Transferring information requires speaking a common language with a patient, namely the national language of the country. In Laos, many people from ethnic minorities do not speak Lao. Some small communities do not even have anyone in the village able to speak the national language.

Moreover, a common language is not enough. Ideas and concepts conveyed through words must have a similar meaning between mothers and informers. Communication requires an intercultural link that is not always present in the field, particularly when health professionals and mothers belong to different cultural groups [7].

\subsection{Inadequate Financial and Human Resources}

One of the main constraints faced by Laos, like so many other developing countries, is the insufficient budget to support direct and indirect nutritional interventions. Some important interventions to fight against malnutrition are not implemented because of limitations in government budgets. There is also in Laos a declining trend in donor funding in support of interventions to address the problem of malnutrition [13].

Laos also suffers from a shortage of quantity and quality of human resources who have the expertise required to design and implement interventions against malnutrition. In addition, there is an unequal distribution of health care personnel across the country. Positions in village health centers located in remote, mountainous, and difficult to access settings, where most ethnic minorities live, are poorly attractive for health care professionals [14]. This lack of resources has an obvious impact on the ability to respond to the needs of information regarding infant feeding.

\subsection{Socio-Cultural, Economic Context}

\subsubsection{Poverty}

Poverty is a determinant of mothers' infant feeding practices as it reduces the ability of households to access adequate quantities of food that meet the nutritional needs of children [8] [10] [15] [16]. 


\subsubsection{Maternal Education Level}

Another commonly found determinant of non-optimal infant feeding is the level of education of the mother [15] [16]. Low education is associated with lower maternal knowledge and unfavorable attitudes regarding infant feeding. A low level of knowledge is statistically associated with energy and micronutrient malnutrition in children [5] [16]. Moreover, it has been shown that mothers who had a higher level of education were more likely to follow public health's feeding recommendations for their children [5]. In Laos, nearly $37 \%$ of women (and $22 \%$ of men) are illiterate [5].

\subsubsection{Beliefs and Traditions}

Laos is an ethnically diverse country. There are 50 officially recognized ethnic groups. Minority groups make up almost half of the country's population. Each ethnic group has its socio-cultural specificities that might affect the behavior of the mother regarding infant feeding [7] [8] [9].

One of the specificities relates to the degree of decision-making autonomy of women in relation to food, which varies considerably from one community to another. Lao women are in a socio-cultural context under varying degrees of domination by their husband and their family. In some cultural settings, trying to introduce a change in children's feeding habits can be a challenge when women need the assent of others, the husband and the family, before doing something different from what they are expected to do according to the ethnic group's traditions [8]. For example, in many Lao communities, mothers receive advice on nutrition and childcare from older women. It has been described that the influence of older women in these households prevents young mothers who would like to follow the advice of health professionals to change the traditional infant feeding practices [17]. In Laos, the role played by grandmothers in household-level decision-making regarding health promotion and disease management is effectively well documented [18].

\section{Determinants of Mother's Behavior Regarding Infants Feeding Practice and the Lao National Nutrition Strategy}

The first (2010-2015) and second (2016-2020) Lao National Nutrition Strategy (NNS) paid special attention to the needs of infant and young children, pregnant women, and lactating mothers. The priority for these groups of the population is the promotion of infant feeding practices that comply with WHO's and United Nations Children's Emergency Fund (UNICEF) recommendations. The strategies evoke education interventions on health and nutrition to pregnant women and lactating women through a variety of means, such as the mass media, networks, and mass organizations, such as the Lao Women's Union and the Family Planning services. They mention that activities to be deployed are expected to address beliefs, traditions, and customs, which might lead to unhealthy nutritional practices, such as food taboos [13] [19].

Activities related to infant feeding practice promoted by the NNS focus on the 
education of pregnant women or those who have just given birth, mainly because mothers are seen as responsible for food offered to their children. The NNS activities assume that if knowledge is improved, attitudes will become more favorable to good feeding practices, which in turn will favorably influence practices [13]. This approach lies on the hypothesis that younger women can autonomously decide which infant feeding behaviors to adopt and that the choice can be modified by providing information on best practices.

The literature showed the importance of the mothers' environment on infant feeding practices. Previous studies found that these practices were influenced by the opinion of other family members especially grandmother and husband who may have misconceptions about optimal feeding practices [20] [21]. The family's influence lies in shared knowledge and understanding of healthy lifestyles that an individual experiences in life [22]. For some mothers, the family's advice could be seen as more valued than those from health professionals [23], because sometimes the advice provided by health professionals is not perceived as practical or answering their children's needs [24].

The approach used by the Lao NNS might therefore be simplistic because it discards the social dynamic that exists in many Lao communities. Indeed, the socio-anthropological literature emphasized the importance of considering human behaviors as the result of a complex interaction between individuals, their families, and the community. The effectiveness of behavior change interventions is strongly modulated by how the social environment affects the capacity to make choices and to act. This is poorly considered in the Lao NNS. Indeed, there is little indication in the NNS document about how feeding traditions in the community should be considered in order to make behavior change efforts more effective. There are no clues on how environmental factors that affect mothers' infant feeding behavior practice should be addressed. The NNS documents are of little help to incite planners and professionals to consider these external factors. In other words, the role of the elders, the extended family, and the community in defining and transmitting socio-cultural norms from one generation to another is largely ignored in early feeding education programs.

Yet, taking into account this aspect could boost the effectiveness of the Lao nutrition program. As stated above, many studies for example have emphasized how mother's behavior is under the guidance of grandmothers. New knowledge in the younger generation can uneasily be mobilized if it confronts the ideas and beliefs of the elders. However, the NNS, with respect to infant feeding, targets only women of childbearing age.

Indeed, the literature showed that targeting only future mothers in interventions aiming at promoting healthy feeding practices is not an optimal strategy [8]. Extending the target population, in particular by including the target grandmothers, might be desirable in Laos because young mothers often rely on their own parents to be informed on how to perform usual tasks, including feeding children [8]. Elderly women in many Lao communities are considered as the guard- 
ians of indigenous knowledge that should preside over the development of children [25]. A systematic review published in 2016 has shown that targeting grandmothers rather than just mothers in behavior change interventions might effectively increase the percentage of mothers practicing exclusive breastfeeding [26]. Fathers and families can effectively play an important role in mothers' decisions regarding breastfeeding practices [27].

In Laos, it has been shown that such a strategy that targets mothers and grandmothers in health promotion activities that address mothers' behavior can be beneficial. Behavior change interventions aimed at grandmothers' knowledge on children's diarrhea treatment increased the percentage of diarrheic children receiving fluids from $30 \%$ to $75 \%$. A side effect of this intervention was also noted on mothers. The percentage of women who continued breastfeeding during the diarrhea episode increased from $73 \%$ to $90 \%$ [25].

To sum up, epidemiological evidence suggested that expanding intervention targets to include the mother's environment may increase the effectiveness of child feeding interventions in Laos [8]. However, this requires decoding the basic principles that underlie the functioning of communities and families. There is a place here for social sciences. Involving social science researchers, such as anthropologists or ethnologists, in the problem definition and the design of behavior change interventions, to take into account the complex dynamics that underlie the functioning of the communities, could prove a profitable investment.

\section{Conclusion}

The Lao national strategy on nutrition in Laos (NNS) aimed at implementing the recommendations of WHO and UNICEF, that is, to reduce the prevalence of malnutrition. We argue that the NNS could be more effective if it considers the relation of power that prevails in Lao communities. In other words, national programs that take into account this relation of power should lead to a more judicious choice of the population targets of public health interventions. The expected outcome would then be a significant improvement of mothers' infant feeding practice. We propose that this should be considered by those who are concerned about the still alarming rates of malnutrition in children in Laos.

\section{Conflicts of Interest}

The authors declare no conflicts of interest regarding the publication of this paper.

\section{References}

[1] World Health Organization (2021) Infant and Young Child Feeding. https://www.who.int/en/news-room/fact-sheets/detail/infant-and-young-child-feeding

[2] Dewey, K. (2001) Guiding Principles for Complementary Feeding of the Breastfed Child.

https://www.who.int/nutrition/publications/guiding_principles_compfeeding_breas 
$\underline{\text { tfed.pdf }}$

[3] World Health Organization (2021) Global Health Observatory (GHO) Data: Child Mortality and Causes of Death.

https://www.who.int/data/gho/data/themes/topics/topic-details/GHO/child-mortali ty-and-causes-of-death

[4] Chaparro, C., Oot, L. and Sethuraman, K. (2014) Laos: Nutrition Profile Nutrition Profile.

https://www.fantaproject.org/sites/default/files/download/Laos-Nutrition-Profile-A pr2014.pdf

[5] Ministry of Health Lao PDR (2018) Lao PDR: Lao Social Indicator Survey II (LSIS II) 2017. https://dhsprogram.com/pubs/pdf/FR356/FR356.pdf

[6] Boulom, S., Essink, D.R., Kang, M.H., Kounnavong, S. and Broerse, J.E. (2020) Factors Associated with Child Malnutrition in Mountainous Ethnic Minority Communities in Lao PDR. Global Health Action, 13, Article ID: 1785736. https://doi.org/10.1080/16549716.2020.1785736

[7] Barennes, H., Simmala, C., Odermatt, P., Thaybouavone, T., Vallee, J., Martinez-Ussel, B., Newton, P.N. and Strobel, M. (2009) Postpartum Traditions and Nutrition Practices among Urban Lao Women and Their Infants in Vientiane, Lao PDR. European Journal of Clinical Nutrition, 63, 323-331. https://doi.org/10.1038/sj.ejen.1602928

[8] De Sa, J., Bouttasing N., Sampson, L., Perks, C., Osrin, D. and Prost, A. (2013) Identifying Priorities to Improve Maternal and Child Nutrition among the Khmu Ethnic Group, Laos: A Formative Study. Maternal \& Child Nutrition, 9, 452-66. https://doi.org/10.1111/j.1740-8709.2012.00406.x

[9] Holmes, W., Hoy, D., Lockley, A., Thammavongxay, K., Bounnaphol, S., Xeuatvongsa, A. and Toole, M. (2007) Influences on Maternal and Child Nutrition in the Highlands of the Northern Lao PDR. Asia Pacific Journal of Clinical Nutrition, 16, 537-545.

[10] Gillespie, A., Creed-Kanashiro, H., Sirivongsa, D., Sayakoummane, D. and Galloway, R. (2004) Consulting with Caregivers: Using Formative Research to Improve Maternal and Newborn Care and infant and Young Child Feeding in the Lao People's Democratic Republic.

http://documents.worldbank.org/curated/en/442081468772480368/Consulting-with -caregivers-using-formative-research-to-improve-maternal-and-newborn-care-andinfant-and-young-child-feeding-in-the-Lao-Peoples-Democratic-Republic

[11] Kaufmann, S. (2003) FAO-Nutrition Country: Laos. http://www.fao.org/3/bc651e/bc651e.pdf

[12] Lao Statistics Bureau and World Bank (2020) Poverty Profile in Lao PDR: Poverty Report for the Lao Expenditure and Consumption Survey 2018-2019. https://thedocs.worldbank.org/en/doc/923031603135932002-0070022020/original/L aoPDRPovertyProfileReportENG.pdf

[13] Ministry of Health Lao PDR (2015) National Nutrition Strategy to 2025 and Plan of Action 2016-2020. http://extwprlegs1.fao.org/docs/pdf/lao168828.pdf

[14] World Health Organization (2013) Human Resources for Health Country Profiles Lao People's Democratic Republic. WHO Regional Office for the Western Pacific, Manila. https://iris.wpro.who.int/handle/10665.1/10528

[15] Kamiya, Y. (2011) Socioeconomic Determinants of Nutritional Status of Children in Lao PDR: Effects of Household and Community Factors. Journal of Health, Population, and Nutrition, 29, 339-348.

[16] Phengxay, M., Ali, M., Yagyu, F., Soulivanh, P., Kuroiwa, C. and Ushijima, H. (2007) Risk Factors for Protein-Energy Malnutrition in Children under 5 Years: Study from Luangprabang Province, Laos. Pediatrics International, 49, 260-265. 
https://doi.org/10.1111/j.1442-200X.2007.02354.X

[17] Talbert, A.W., Ngari, M., Tsofa, B., Mramba, L., Mumbo, E., Berkley, J.A. and Mwangome, M. (2016) When You Give Birth You Will Not Be without Your Mother: A Mixed Methods Study of Advice on Breastfeeding for First-Time Mothers in Rural Coastal Kenya. International Breastfeeding Journal, 11, Article No. 10. https://doi.org/10.1186/s13006-016-0069-6

[18] Aubel, J., Sihalathavong, D. and Kopkeo, D. (1997) Participatory Health Education Project with Grandmothers in Laos. The Grandmother Project, Maryland.

[19] Ministry of Health Lao PDR (2009) National Nutrition Strategy and Plan of Action 2010-2015. http://www.fao.org/3/at539e/at539e.pdf

[20] Hamilton, W.N. (2020) Factors Influencing Maternal Decision-Making on Infant Feeding Practices. Infant Feeding-Breast versus Formula. IntechOpen, London. https://www.intechopen.com/chapters/71427

[21] Radzyminski, S. and Callister, L.C. (2016) Mother's Beliefs, Attitudes, and Decision Making Related to Infant Feeding Choices. The Journal of Perinatal Education, 25, 18-28. https://doi.org/10.1891/1058-1243.25.1.18

[22] Scaglioni, S., De Cosmi, V., Ciappolino, V., Parazzini, F., Brambilla, P. and Agostoni, C. (2018) Factors Influencing Children's Eating Behaviours. Nutrients, 10, Article No. 706. https://doi.org/10.3390/nu10060706

[23] Heinig, M.J., Ishii, K.D., Bañuelos, J.L., Campbell, E., O’Loughlin, C. and Vera Becerra, L.E. (2009) Sources and Acceptance of Infant-Feeding Advice among Low-Income Women. Journal of Human Lactation, 25, 163-172. https://doi.org/10.1177\%2F0890334408329438

[24] Russell, C.G., Taki, S., Azadi, L., Campbell, K.J., Laws, R., Elliott, R. and Denney-Wilson, E. (2016) A Qualitative Study of the Infant Feeding Beliefs and Behaviours of Mothers with Low Educational Attainment. BMC Pediatrics, 16, Article No. 69. https://doi.org/10.1186/s12887-016-0601-2

[25] Aubel, J. (2006) Grandmothers Promote Maternal and Child Health: The Role of Indigenous Knowledge Systems' Managers.

https://openknowledge.worldbank.org/bitstream/handle/10986/10745/354580REV0 Grandmothers0iknt89.pdf?sequence $=1$

[26] Negin, J., Coffman, J., Vizintin, P. and Raynes-Greenow, C. (2016) The Influence of Grandmothers on Breastfeeding Rates: A Systematic Review. BMC Pregnancy and Childbirth, 16, Article No. 91. https://doi.org/10.1186/s12884-016-0880-5

[27] Ogbo, F.A., Akombi, B.J., Ahmed, K.Y., Rwabilimbo, A.G., Ogbo, A.O., Uwaibi, N.E., Ezeh, O.K. and Agho, K.E. (2020) Breastfeeding in the Community-How Can Partners/Fathers Help? A Systematic Review. International Journal of Environmental Research and Public Health, 17, Article No. 413. https://doi.org/10.3390/ijerph17020413 